\title{
LA PALABRA NACIENTE. LA COMPRENSIÓN GADAMERIANA DEL LENGUAJE EN DIÁLOGO CON LA FILOSOFÍA ANALÍTICA
}

\author{
Luis SAEZ RUEDA \\ Universidad de Granada
}

RESUMEN. El trabajo analiza la dimensión fenomenológica del lenguaje (el "acontecimiento" del "habla", o del «decir») como una esfera de significación que no es objetivable y que forma parte de una experiencia «en estado naciente». Esta concepción lingüística, frecuente en la filosofía continental, es explicitada tomando como prisma la hermenéutica de Gadamer. Dicha comprensión de la vida del lenguaje se confronta con concepciones "homólogas" de la filosofia analítica (la teoría de los actos de habla, el externalismo davidsoniano y el pragmatismo wittgensteiniano) con el fin de confirmar la existencia de un simultáneo paralelismo estructural e hiato ontológico entre las tradiciones filosóficas "continental" $\mathrm{y}$ "analítica».

$E l^{1}$ rayo lo guía todo. Esta frase, inscrita en griego, en una corteza de árbol, presidía la entrada a la cabaña de Heidegger en Todtnauberg ${ }^{2}$. De ella dice Gadamer que constituye un apretado compendio de toda la filosofía del maestro: lo que se nos hace presente y nos es dado vive en el instante iluminador de la comprensión y presto a sustraerse en el ocultamiento. «Está claro — sentencia el hermeneutaque la ingente tarea del pensamiento consiste en hacer que esa iluminación ins-

1 Este trabajo se ha realizado con ayuda del MCYT, a través del Proyecto de Investigación "Nihilismo y Metafísica", n. ${ }^{\circ}$ de ref.: BFF2002-02423. Dicho proyecto está cofinanciado con FEDER.

2 La expresión es de Heráclito: Diels-Kranz (Die Fragmente der Vorsokratiker), 22 B 64.

${ }^{3}$ H.-G. GaDAMER, "Heidegger y el final de la filosofía" (orig. de 1984), en Acotaciones hermenéuticas, Trotta, Madrid, 2002, p. 254; cfr. pp. 252-255. 
tantánea del rayo, que en un momento genera claridad, pase a ser algo permanente, refugiándose en la palabra y deviniendo discurso que alcanza a todos» ${ }^{3}$.

Aquí está dicho lo que este trabajo desea comentar y esclarecer, en honor a uno de los más grandes pensadores de nuestra época. La palabra se relaciona con el mundo de un modo muy peculiar. No da representación a hechos mediante una estructura proposicional, sino que acoge y arropa la donación de la experiencia. Al prodigarle refugio a ésta, no le confiere la permanencia de las Ideas platónicas ni la inmortaliza como presencia muda y estática; su tarea es la de sostener la emergencia de su ser comprensible y hacerla perdurable en el devenir del diálogo. En todo ello se pone de manifiesto ante todo un modo de ser de la palabra, fascinante y enigmático: ésta cumple su auténtico cometido en la medida en que da espacio al acontecimiento, al movimiento mismo del venir a presencia. ¿Y cómo podría lograrlo si ella misma no se comporta, al unísono, como acontecimiento? La palabra no está en el hablante "como el agua en el vaso" ; acontece: está siendo mientras se habita en el hablar. Pero si su esencia es ese ser-existiendo, no ha sido alumbrada de una vez por todas: la palabra es naciente e ilumina, como el rayo, el sentido del mundo, al que da la palabra.

Éste es el misterio al que quisiera aproximarme en este trabajo. Pero, también en honor a Gadamer, que destina la palabra al juego del diálogo, pretendo abordar el problema intentando dialogar con la concepción analítica del lenguaje, indagando de qué modo puede hoy hacerse pertinente la filosofía hermenéutica en orden a esa inter-locución entre tradiciones, continental y anglosajona, hoy tan necesaria como precaria ${ }^{5}$. El mismo Gadamer, por cierto, invita expresamente a perseguir el enlace entre estos dos territorios del pensamiento, cuya distancia caracteriza como «el mayor foso de carácter filosófico que existe hoy entre los pueblos» ${ }^{6}$.

4 Heidegger ilustra así la peculiar forma de ser del Da-sein como ser-en-el-mundo. Como se sabe, el en de esta expresión no expresa una relación de contigüidad o de inclusión espacial. Significa habitar, ser-cabe, curarse de. M. HEIDEGGER, Ser y Tiempo, FCE, Madrid-México, 1982 (orig.: 1927), \$ 12 .

5 He intentado perfilar los encuentros y desencuentros entre estas dos tradiciones, de un modo general, en L. SAEZ RuEDA, El conflicto entre continentales y analiticos, Crítica, Barcelona, 2002. El presente ensayo incorpora la tesis central de dicho trabajo y pretende aplicarla al caso de la hermenéutica gadameriana, que adolece allí de un insuficiente tratamiento.

${ }^{6}$ GaDAMER, Verdad y Método, II, Salamanca, Sígueme, 1992 [en adelante VM, II], p. 76. 
Con el fin de interrogar sobre ese "foso" y de poner en obra, por medio de esta estrategia, la filosofía del lenguaje gadameriana, mi reflexión seguirá el siguiente cauce. En primer lugar, esbozaré el marco general de discusión entre continentales y analiticos, que comprendo desde la óptica del contraste entre una ontologia del acontecimiento y una ontologia de la factualidad, perfilando, al mismo tiempo, el lugar específico de Gadamer en dicho contexto $(\$ 1)$. A continuación intentaré mostrar tres rostros de la concepción que del lenguaje tiene nuestro filósofo, aprovechando la confrontación con la filosofía analítica: en diálogo con la teoría de los actos de habla, abordaré el ser irreglable de la palabra $(\$ 2)$; como acontecimiento de conversación aparecerá ésta en conexión con el externalismo de Davidson ( $\$ 3$ ); a propósito de Wittgenstein y de sus herederos, finalmente, escrutaré el nexo entre la indisponibilidad del decir y la responsabilidad ética que éste presupone $(\$ 4)$.

\section{Gadamer y el contraste entre ontología del «acontecimiento» y ontología de la «factualidad"}

La noción de acontecimiento, a la que remite la concepción gadameriana de la palabra, no es marginal en el pensamiento del siglo XX. Constituye, a mi juicio, el horizonte de una ontología que subtiende el discurrir entero de la filosofía continental y contrasta, como veremos, con una ontología de la factualidad, propensión global en el panorama analítico. Para aclarar esa persistencia habría que reparar, antes de nada, en la circunstancia de que la filosofía del continente ha seguido, desde Husserl, un tortuoso trayecto cuya vocación subterránea es la de una mundanización del sentido. Valga en el presente contexto una apretada semblanza ${ }^{7}$. En la fenomenología encontramos, en primer lugar, el umbral de una comprensión del mundo cuyas claves fundamentales residen en las nociones de retroceso al mundo de la vida y de ontología del sentido. La epoché procura un retroceso mediante el cual lo real se redescubre tal y como es experimentado en la esfe-

${ }^{7}$ El esbozo general que aquí propongo ha sido objeto de un análisis más preciso y extenso en otros lugares. Para una inspección de lo que llamo mundanización del sentido, véase L. SAEZ RUEDA, Movimientos filosóficos actuales, Trotta, Madrid, 2001, esp., Introducción y los parágrafos 1.3., 2.3., 4.1 6.3., 13.1 y 16.1. Un análisis más comprimido se encuentra en L. SAEZ RUEDA, El conflicto entre continentales y analiticos, op. cit. pp. 65-93. Respecto a la ontologia del acontecimiento que atraviesa dicho proceso y su contraste con la analítica ontología de la factualidad, véase L. SAEZ RUEDA, Movimientos filosóficos actuales, op. cit., pp. 24-26 y caps. 9.1 y 10.4.; El conflicto entre continentales $y$ analiticos, op. cit., especialmente cap. 2.3. 
ra constituyente del sujeto, es decir, como un aparecer por mor del cual se muestra en el cómo de su ser-vivenciado. El mundo es, así, un plexo de "fenómenos de sentido", de modos de ser que hacen acto de presencia en el hábitat sintiente de la subjetividad. El retroceso al mundo de la vida y su pareja ontología del sentido se han revelado, desde la aurora del siglo, como principios dinamizadores que, de forma asombrosamente plástica, se modulan a través de múltiples investiduras, al precio, sin embargo, de una profundización en la que se acelera lo que podríamos caracterizar como mundanización. Si la fenomenología que promovió Husserl arraigó la comprensión del ser en la esfera intramundana del sujeto, la fenomenología postidealista y existencial exacerbó esa especie de regreso a la tierra de la vida. Aunque con matices diversos, tanto la ontología fundamental de Heidegger como la fenomenología de la carne de Merleau-Ponty, contribuyeron a una desfundamentación del sujeto y a una eventualización del sentido. $\mathrm{El}$ sujeto, agente del mundo de la vida, se descubre ahora inmerso en una facticidad que lo trasciende y lo constituye desde un fondo previo. Y ese giro hacia las profundidades desvela, al mismo tiempo, que el sentido inherente a los fenómenos del mundo no lo constituye el sujeto, sino que emerge a sus espaldas, desde una terra ignota que es existencia heraclítea y multiforme en la que el hombre se hospeda como un ser arrojado y siempre en tránsito. A la irresistible fuerza de esta primera profundización de lo mundano, no pudieron sustraerse ni siquiera sus enemigos, los ilustrados (Habermas, Apel), que intentan vincular sentido y validez ${ }^{8}$. Se trata de una inflexión muy distinta a la que tiene lugar en el espacio de esa fase postrera, la del pensamiento postmoderno. Ni siquiera en esta última claudica la ontología del sentido. Más bien se la somete a una transgresión desde dentro o profanación. El pensador ultramoderno, en efecto, se instala en el templo ontológico del sentido para desvelar su faz irreverente. Es la ausencia de ese protofenómeno (el ser heideggeriano) que asistía al devenir desde las profundidades como si fuese una añorada divinidad y cuyo declive inyecta en el esplendor del sentido la mácula de su carácter radicalmente efímero (Vattimo). Es la copertenencia inexcusable entre pre-

${ }^{8}$ Tuvieron que entender la racionalidad, empujados por el retroceso al mundo de la vida, como una razón centrada o intramundana, inserta en la praxis comunicativa cotidiana. La mundanización no se paraliza en esta etapa: es corregida, en la medida en que la constitución del sentido se media ahora con la justificación de la validez en un proceso histórico infinito. Cfr. J. HABERMAS, Pensamiento postmetafisico, Taurus, Madrid, 1990 (orig.: 1988), cap. I; K.-O. APEL, "Constitución de sentido y justificación de validez. Heidegger y el problema de la filosofía trascendental", en J. M. Navarro Cordón/R. Rodríguez (comps.), Heidegger o el final de la filosofia, Ed. Complutense, Madrid, 1993 (orig.: 1989). 
sencia y despresencia, que convierte al sentido en una promesa siempre diferida y, así, en una huella de lo que pretende mostrar (Derrida, Lyotard).

Al poner de manifiesto el vasto alcance de este proceso de mundanización del sentido puede apreciarse la sorprendente persistencia de la ontología del acontecimiento. El filósofo continental no ha cesado de describir el mundo como conteniendo una dimensión vertical de acontecer dinámico. Ya para la fenomenología husserliana los fenómenos son realidades emergentes, pues el sentido existe sólo en la medida en que está siendo experimentado. El acto dinámico del experimentar se corresponde con una realidad experimentada que es el movimiento mismo del mostrarse como un modo de ser, como un ser-así, tal y como está apareciendo en la vivencia?. Ese siendo dinámico de la realidad se profundiza en los movimientos ulteriores: es un aconteciendo el mundo, en la medida en que está siendo aprehendido desde las posibilidades de la existencia (Heidegger) o en que habitamos corporalmente el espacio (Merleau-Ponty). No es, finalmente, una realidad objetiva, apolínea, la historia del acaecer contingente que Vattimo contempla. Ni esa hibridación de presencia y ausencia, en la que el pensador de la diferencia cifra la clave del ser: la experiencia que este filósofo hace del mundo es la de un estar presentándose los sucesos ante nosotros como siendo huella de una ausencia. En suma, para la filosofía continental del siglo XX no hay objetos, sino acontecimientos. La ontología del acontecimiento reconoce en la textura de lo real una dimensión dinámica que el término "fenómeno" hereda del griego. Es la dimensión vertical de emergencia significativa, algo distinto a la dimensión horizontal de la significación como contenido. Una ontología así le reconoce a lo real un elemento irrepresentable, no reconstruible como "objetividad". Se podría decir de ella que es articulable en un juego de lenguaje en el que cabe oponer "fuerza-significativa» a "significado acotable», "intensidad vertical» a "extensión horizontal", "dinamicidad" a "estatismo", "enérgeia" a "forma".

Es precisamente este remate el que permite aprehender, en un sentido contrastante, la propensión inmanente al pensamiento analítico, una propensión que quisiera describir, de entrada, de un modo genérico. Antes de nada hay que decir, sin embargo, que el contraste se yergue sobre una comunidad de fondo que resultará sorprendente al investigador atento. Pues lo que hemos llamado

${ }^{9}$ E. HusSERL, Meditaciones cartesianas, Paulinas, Madrid, 1979 (Ha., I), especialmente $\$ \$ 1$, 2, 8, 9 y 14 . 
mundanización del sentido posee una semejanza estructural profunda con el decurso que la filosofía analítica ha experimentado en la pasada centuria. Se trata, en este caso, de un proceso de naturalización del significado, en virtud del cual se desafía al idealismo fregeano y se propende a incardinar los procesos de significación en las transacciones inmanentes al mundo natural ${ }^{10}$. En ambas tradiciones, podríamos decir, se ha instalado un mismo impetus: el de asestar un golpe de muerte a la inmaculada idealidad del sentido (o del significado) para retrotraerlo al espacio intramundano de la existencia natural. Ahora bien, lo que se entiende por "natural» es, en cada caso, distinto. Para el continental, coincide con el inobjetivable mundo de la vida, habitado por esa forma moderna de natura naturans que es el acontecimiento. Para el analítico, en cambio, constituye un plexo de relaciones explicitables en el plano horizontal-léase, siguiendo el símil, natura naturata - de las relaciones legaliformes o de los hechos descriptibles ${ }^{11}$. Comparada con la continental, la filosofía analítica propende a una mundanización del significado a través de una ontología de la factualidad, en la medida en que comprende lo real como un espacio entitativo designable o reconstruible en descripciones o explicaciones legaliformes. Pero lo factual no se reduce a lo «empírico" o "comprobable» tal y como es usual en una concepción típicamente verificacionista. Coincide, en su sentido más amplio, con aquello que es susceptible de una representación o descripción acotable proposicionalmente. Si para expresar el carácter irrepresentable del acontecimiento hemos hecho uso de términos contrastantes, podríamos servirnos aquí de una oposición pensada por Wittgenstein en las Investigaciones filosóficas, cuando se refiere a la diferencia entre "expresiones gramaticales" y "expresiones factuales (o empíricas)" ${ }^{12}$. Lo factual,

${ }^{10}$ Si la mundanización del sentido continental incorpora, como uno de sus principios dinamizadores, una reacción al idealismo husserliano, la naturalización del significado atraviesa toda la trayectoria analítica portando, expresa o tácitamente, una reacción contra el idealismo fregeano. Cfr. J.J. ACERO FERNÁNDEZ, "Después del análisis: significado, comprensión e intencionalidad», en $\mathrm{M}$. Torrevejano (ed.), Filosofia analítica boy. Encuentro entre tradiciones, Univ. de Santiago de Compostela, 1991, pp. 9-25; L. SAEZ RUEDA, El conflicto entre continentales y analíticos, op. cit., cap. 2.2.

11 "Naturalización del significado" quiere decir, como paradigmáticamente expresa Fodor, un requisito ontologico general según el cual los fenómenos de significación son explicables, bien como realidad del orden físico-natural, bien como realidad en continuidad con dicho orden. FoDOR, The Elm and the Expert, The M.I.T. Press, Cambridge, 1993, p. 5.

12 Las primeras son aquellas que, en un "juego de lenguaje" determinado expresan elementos inmanentes que caracterizan el tipo de uso, praxis o forma de vida entretejidos en ese marco. Tales elementos sólo pueden ser "mostrados". No pueden ser "dichos", es decir, utilizados en proposiciones «factuales", respecto a las cuales actúan como condición de significatividad: son los goznes 
siguiendo la distinción wittgensteiniana, es siempre un contenido que puede ser dicho y acotado mediante una descripción, pero presupone un campo de juego que sólo se muestra y no puede ser representado. Puede adoptar diversas formas. No es necesario que lo confinemos al campo de la experiencia científico-natural; cabe que se refiera al de las ciencias humanas, a lo social, lo histórico o lo cultural. Pero es el caso que adopta la forma de un discurso proposicional y representativo. En este discurso pone su fe el analítico, como quisiera mostrar.

Llegados a este punto, el pensamiento de Gadamer cobra una especial significatividad, pues constituye un punto de mira eminente para auscultar el conflicto entre estas dos tradiciones. Es obvio que puede incluirse en el proceso de mundanización del sentido esbozado. Y no sólo porque es heredero de esa hermenéutica de la existencia con la que Heidegger profundizó la fenomenología, sino porque dotó a lo que he llamado eventualización del sentido con un léxico profundamente clarificador. Por medio de nociones como historia efectual o fusion de horizontes explicitó la textura del discurrir histórico del sentido, mostrando a un tiempo que éste está ya siempre circunscrito en horizontes e inscrito en un diálogo interminable. Al hacerlo, testimonió la ontología del acontecimiento del proceso de mundanización — «El carácter de acontecer forma parte del sentido mismo. Es como en una maldición, que evidentemente no se puede separar de que la pronuncie alguien» ${ }^{13}$ - e hizo comprensible la "productividad del acontecers $^{14}$.

Pero si el caso gadameriano es especialmente relevante en esta problemática es, ante todo, porque hizo coincidir la ontología del acontecimiento con una ontología lingüística. El aserto emblemático al respecto se ha convertido ya en un tópico:

del juego, de los que depende la textura del «mundo». Una lectura hermenéutica atribuiría a tales elementos el carácter del acontecimiento (acontecen al mostrarse). Las proposiciones factuales, por el contrario, acotan un espacio de realidad en el mundo y lo describen como un conjunto de hechos dados, como contenidos representables: L. WITTGENSTEIN, Investigaciones filosóficas, Crítica, Barcelona, 1988 (orig.: 1953), p. ej., $\$ \$ 251,295,458$.

13 Verdad y Método, Sígueme, Salamanca, 1977 (orig.: 1951) [en adelante VM, I], p. 512. La conformación de la experiencia hermenéutica como un acontecer puede rastrearse en infinidad de lugares de la obra gadameriana. Basten los siguientes: en conexión con el concepto de historia efectual, ibid., pp. 375 ss.; con el de aplicación, ibid., 380 s.; con el de pregunta, ibid., pp. 451 s., 551 555 y $563-565$.

14 Ibid., p. 367; cfr. pp. 363-370. 
"El ser que puede ser comprendido es lenguaje» ${ }^{15}$. Es ahora cuando el legado de Gadamer nos sale al encuentro con la virtualidad del rayo. Poniéndolo en obra podríamos iluminar lo que acontece en el encuentro entre las tradiciones continental y analítica, con el fin de acogerlo y sostenerlo en la palabra y con la intención de que esa pesquisa persista en el conversar. El camino idóneo es, sin duda, el que inquiere sobre la diferencia allí donde el acuerdo tácito parece estar asegurado.

\section{La palabra como apertura irreglable. En diálogo con la teoría de los actos de habla}

Un ámbito analítico cuya comunidad de fondo con el continental sale al encuentro con especial vigor es el de la teoría de los actos de habla, que debemos a Austin y Searle. Con la perspectiva de una avanzada edad, Gadamer mismo señaló ese lugar privilegiado ${ }^{16}$. Y es natural, pues la concepción de estos autores destapó la ligazón entre la lengua y el hablante.

Para desembarcar en esa costa anglosajona sin naufragar es necesario recordar, en primer lugar, los tesoros más conocidos que el barco gadameriano porta en su bodega. Habría que destacar, así, la universalidad de la experiencia lingüistica. Hay al respecto tres argumentos interesantes. El primero evoca el dictum wittgensteiniano según el cual los límites del lenguaje son los del mundo: en el ser-lingüístico habitamos inexorablemente, porque una supuesta representación objetivante de su latencia tendría que ser, ella misma, pensada lingüísticamen$\mathrm{te}^{17}$. El segundo invoca a Aristóteles e incide en la originariedad del lenguaje: él permite la distancia que exige el aparecer de lo real ${ }^{18}$. El tercero afronta la supo-

15 Ibid, p. 567.

16 "Acerca de la verdad de la palabra" (1971), en Arte y verdad de la palabra, Paidós, Barcelona, 1998, pp. 15-17.

17 "Sólo podemos pensar dentro del lenguaje, y esta inserción de nuestro pensamiento en el lenguaje es el enigma más profundo que el lenguaje propone al pensamientom. $V M, \mathrm{II}, \mathrm{p} .147$.

${ }_{18}$ El lenguaje, como pensaba Aristóteles, sustrae al hombre de la ciega inmediatez y le permite colocarse ante la realidad. Gadamer señala la primacía que posee el oir sobre el ver, ya afirmada por el estagirita. Es la palabra la que, en último término, propicia que lo que es se nos muestre, aunque no esté presente. Cfr. Arte y verdad de la palabra, op. cit., 132-136. En el presente trabajo, y en diversos contextos, el lector podrá comprobar la fascinación de Gadamer por el pensamiento aristotélico. Gadamer no duda en exigir que la filosofía de Aristóteles sea leída con mayor atención, en virtud de su fecundidad para esclarecer los problemas de nuestra actualidad (Cfr. ibid., p. 132). Teresa Oñate ha hecho honor con maestría a esta demanda. Véase T. OÑatE y ZuBLA, Para leer la Metafisica de Aristotteles en el siglo XXI, Dykinson, Madrid, 2001. 
sición de que hay comunicación pre-lingüística: cierto, pero no es extralingüística, pues adquiere sentido sólo en el medium del lenguaje ${ }^{19}$.

Esta adscripción plena de Gadamer al giro lingüístico autoriza el diálogo con el analítico. Ahora bien, es necesario aún recordar un segundo aspecto del posicionamiento gadameriano, que resulta crucial, a saber, que la universalidad de la experiencia lingüistica es coincidente con la universalidad de la experiencia hermenéutica del comprender. Sin entrar en detalles, esto significa que el ser del lenguaje se cifra en su poder para hacer mundo, en que constituye el subsuelo desde el que tiene lugar la apertura de sentido sobre la que se yergue cualquier

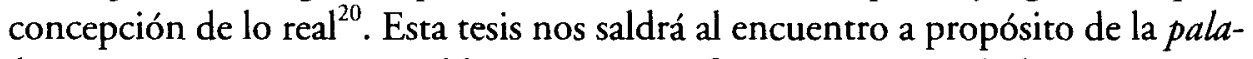
$b r a$, pues, como veremos, el lenguaje se conforma como un diálogo y es manifiesto que la esencia del dialogar se aquilata en la del decir.

Para explicitar esta idea central, llamo la atención sobre el modo en que Gadamer ilumina la relación entre el lenguaje proposicional y el fenómeno del habla. El enunciado, portador de un contenido referencial y designativo, no posee una existencia autónoma. Se inserta en un contexto de habla, en el cual se gesta su sentido $^{21}$. La desvinculación de la lógica enunciativa respecto a este suelo constituyente es precisamente lo que caracteriza al proyecto logicista de formalización del lenguaje natural y, en general, a la objetivación de lo existente que inspira al cientificismo y que se nutre de lo que, en términos heideggerianos, puede ser denominado voluntad técnica de dominio de la metafisica de la presencia ${ }^{22}$. En todo ello reconocemos la profunda vinculación de Gadamer con la continental fenomenologia del habla, de la que Heidegger y Merleau-Ponty son destacados

19 «Esto quiere decir que lo prelingüístico está siempre, en cierto sentido, de camino a lo lingüístico" (Gadamer, ibid., p. 142). Gadamer afronta así fenómenos tales como el de la risa ("quien ríe dice algo", ibid., p. 140), el asombro y la muda admiración (VM, II, pp. 181 s.), los simbolismos de los lenguajes construidos por la ciencia ( $V M, \mathrm{I}, \mathrm{p} .200)$ o el poder y el trabajo, esferas que, según Habermas en sus incisos críticos, escaparían al espacio lingüístico ( $V M, I I$, 198 ss.).

${ }^{20}$ El locus privilegiado de la producción gadameriana al respecto es, quizás, $V M, \mathrm{I}, \$ \$ 12-14$.

${ }^{21}$ Véase VM, II, pp. 189-191. Ni siquiera Aristóteles, contra el prejuicio extendido, separa la dimensión apofántica del lenguaje del contexto pragmático en el que se usa (súplica, maldición, mandato...). Véase ibid., p. 189.

${ }^{22}$ Cfr., p. ej., ibid., pp. 190 s., 198-201 y "Heidegger y el final de la filosofía" (1984), en Acotaciones hermenéuticas, op. cit., esp. pp. 240-245. 
promotores ${ }^{23}$. Pero lo fundamental en el problema que nos ocupa es que muestra semejanzas sorprendentes con la analítica teoría de los actos de habla, que ha sido desplegada por J. Searle y que fue iniciada por J. Austin ${ }^{24}$. Tan próxima resulta al continental que Derrida ${ }^{25}$ ha destacado la incipiente desconstrucción de la metafisica de la presencia que es apreciable en su apuesta principal, a saber, que el significado de las proposiciones es dependiente de una dimensión de fuerza -la fuerza ilocucionaria-, implícita en el acto de habla y responsable de su productividad performativa: con él no se "representan" hechos, sino que se hacen cosas.

Encontramos aquí una semejanza estructural con la ontología del acontecimiento, pero también un hiato. Aunque los actos de habla porten una fuerza significante, ésta arraiga en una praxis que Searle comprende como un "sistema de reglas" ${ }^{26}$. Ciertamente, éstas no son "hechos brutos", sino "hechos institucionales", convenciones humanas. Pero, en cualquier caso, se trata de factualidades en el sentido amplio antes referido: son representables en un lenguaje designativo. Coherente con ello es que sean caracterizadas como condiciones de la realización exitosa de los actos de habla y que puedan ser reconstruidas mediante el examen de las circunstancias "normales" y «ordinarias» en las que éstos desempeñan su papel "paradigmático" 27.

La diferencia con Gadamer se hace patente cuando éste invita a reparar en que el uso de las palabras presupone la competencia lingüistica, "algo que ya no se puede definir describiendo la correcta aplicación de una regla, sino que salta por encima de cualquier justificación mediante reglas». El decir surge de un fon-

${ }^{23}$ Tanto en uno como en otro se caracteriza al habla como una dimensión ontológico-existencial que es responsable de la apertura del mundo y como una dimensión de acontecimiento constituyente respecto a la dimensión proposicional del lenguaje expreso. M. HEIDEGGER, El ser y el Tiempo, FCE., México, 1982 (orig.: 1927), $\$ \$ 28$ y 34. M. MERLEAU-PONTY, Fenomenología de la percepción, Península, Barcelona, 1975 (orig.: 1945), primera parte, cap. VI.

${ }^{24} \mathrm{~J}$. AUSTIN, Cómo hacer cosas con palabras: palabras y acciones, Paidós, Barcelona, 1982 (orig.: 1962).

${ }^{25}$ J. DERRIDA, Márgenes de la filosofia, Cátedra, Madrid, 1989, pp. 347-372. Cfr. pp. 362 ss.

${ }^{26}$ Cfr. J. SEARLE, Actos de habla, Cátedra, Madrid, 1980 (orig.: 1969), pp. 25 y, en general, $\$ \$$ 2.5. y 2.7 .

${ }_{27}$ J. Austin, Cómo hacer cosas con palabras, op. cit., caps. II-IV; J. Searle, Actos de habla, op. cit., cap. III. Se trata, por ejemplo, de las reglas en virtud de las cuales podemos decir que un acto de promesa ha cumplido su cometido. 
do irreglable que, por cierto, convierte a la palabra exitosa precisamente en lo más extraordinario. «Un insatisfecho deseo de la palabra pertinente: probablemente esto sea lo que constituye la vida y la esencia verdaderas del lenguaje» ${ }^{28}$.

Que el habla sea acontecimiento puede ser aclarado, en este contexto, del modo siguiente: su ser es el movimiento mismo en virtud del cual son generadas reglas sin recurso a reglas preexistentes. De esta fascinante cualidad da testimonio el modo en que, según nos explica Gadamer, se gestan nuestros conceptos generales. En ellos se explicita una regla, pero ésta surge de un modo preconceptual e irreglamentado, lo cual ocurre también en el aprendizaje de la lengua. Sucede en estos procesos que partimos de un cambiante flujo de impresiones y las organizamos en unidades, mediante un continuum procesual sin comienzo, tal y como ocurre en la detención de un ejército que huye, según el ejemplo de Aristóteles ${ }^{29}$. Una conclusión coherente, por cierto, con aquella a la que se ve conducido Merleau-Ponty en el análisis de nuestra inserción carnal en el mundo. La organización prerreflexiva de la experiencia, nos aclaraba el fenomenólogo, se ejerce en virtud de la orientación corporal hacia tareas. Esa actividad prospectiva de la inteligencia conduce a resultados que son reconstruibles como reglables sólo a posteriori, pero no puede ser explicada como el seguimiento de una regla antecedente. Semejante capacidad para anticipar reglas sin regla es la enigmática productividad que permite hablar del sujeto como ser-salvaje ${ }^{30}$.

${ }^{28}$ H.-G. GADAMER, Arte y verdad de la palabra, op. cit., pp. 148 y 149.

${ }^{29}$ Gadamer recurre con frecuencia al ejemplo que Aristóteles utiliza para aclarar la adquisición de conceptos generales a partir de impresiones cambiantes (Aristóteles, An. Post. B 19, 99 b 35 s.) ¿Cómo se produce en esa fuga heraclítea un orden? ¿Cómo se restablece el arché, la unidad de mando? Un soldado se detiene, al cerciorarse de la lejanía del enemigo, y a él le siguen otros. Nadie en particular controla el proceso, y éste no es explicable como la suma de acciones individuales. "Cuando uno se detiene, todavía no ha terminado la huida, ni tampoco cuando se detiene el segundo o el tercero. Y, a fin de cuentas, nunca se sabe cómo llega a detenerse el ejército. (...) Ésta es la descripción de un comienzo sin comienzom. H.-G. GADAMER, Arte y verdad de la pala$b r a, o p$. cit., p. 137. La retención del flujo de experiencia en un principio de unidad posee una textura similar. Ocurre también en el aprendizaje del lenguaje. Si se llega a comprender es en la medida en que se alcanza un "orden" y un entendimiento intersubjetivo. Ahora bien, lo extraordinario es que "no hay en él ningún comienzo, sino que es precisamente en el sentido literal de la expresión un convenir, un continuum del tránsito (...)", ibid., p. 138. Véase también "Hombre y lenguaje» (1965), en VM, II, pp.148-150 o "Lenguaje y comprensión" (1970), en ibid., pp. $196 \mathrm{s.}$

${ }^{30} \mathrm{He}$ aquí el compositor, cuya sinfonía lograda responde globalmente a un corpus de reglas. Pero, in medias res, cuando enlazaba un sonido con el anterior no disponía todavía de éstas. Las anticipaba, como una especie de esbozo. Una anticipación imaginativa e irreglable del resultado 
Pero para aprehender la sutileza implícita en la distinción entre las ontologías del acontecimiento y de la factualidad, hemos de hacer frente aún a una posible objeción. Searle ha reconocido que los actos de habla presuponen un trasfondo contextual integrado por "capacidades mentales, disposiciones, posturas, modos de comportarse, saber cómo, savoir faire, etco, un subsuelo que es irrepresentable en reglas, pues las «reglas no se autointerpretan y, en consecuencia, requieren un trasfondo para funcionar ${ }^{31}$. Pues bien, tal y como lo describe el analítico, el trasfondo irreglabe no es plenamente constituyente respecto a la regla, sino que supone la existencia de ésta en cuanto tal. A lo que Gadamer apunta no es a la circunstancia de que en el habla tiene lugar la interpretación de reglas, sino a que el acontecimiento mismo del interpretar genera la regla, la cual, por cierto, ni siquiera constituye un resultado estático, sino también un fenómeno dinámico: un "ponerse de acuerdo", un "convenir, un continuum del tránsito" ${ }^{32}$. La esencia del lenguaje es el acontecimiento vertical del significar mismo. «Ser palabra quiere decir ser dicientes ${ }^{33}$. Lo expresó Merleau-Ponty con admirable belleza: el lenguaje genuino es aquel que vibra como palabra hablante, en cuyo seno la signficación está en estado naciente ${ }^{34}$. Se comprenderá ahora la diferencia. Para Searle, al fin y al cabo, la esencia del lenguaje se cifra en factualidades: reglas o contenidos que resultan de la aplicación interpretativa ${ }^{35}$.

es lo que, según Merleau-Ponty «arranca» nuestros movimientos en la orientación espacial, nuestros argumentos concretos en la formación del pensamiento o las palabras precisas en la gestación del discurso. Cfr. M. MERLEAU-PONTY, Fenomenologia de la percepción, op. cit., parte primera, caps. III y IV.

31 J. SEARLE, El redescubrimiento de la mente, Barcelona, Crítica, 1996 (orig.: 1992), pp. 198 y 201 ; cfr. $\$ 8$.

${ }^{32}$ H.-G. GADAMER, Arte y verdad de la palabra, op. cit., p. 138.

33 Ibid., p. 20, véase además pp.15-22.

${ }_{34}^{34}$ M. MERLEAU-PONTY, Fenomenología de la percepción, op. cit., p. 213; cfr. pp. 191-216.

${ }^{35}$ No basta con admitir un fondo irrepresentable para ingresar en una ontologia del acontecimiento. Es necesario que a dicho fondo se le otorgue un carácter dinámico y que se cifre en él lo sustancial. No es seguro que Searle suponga lo primero, pues elementos como "capacidades" y "disposiciones" no excluyen a priori la posibilidad de su representación proposicional (por las ciencias de la conducta). Es seguro, me parece, que no acepta lo segundo. Aunque surja de una interpretación, el significado es para Searle un resultado estático. En su fase más reciente, la de la filosofia de la mente, entiende los elementos del lenguaje como contenidos de estados mentales, que se caracterizan, por lo demás, por su capacidad representacional para ureferir a objetos y estados de cosas del mundo que están más allá de esos mismos estadosm. J. SEARLE, Razones para actuar, Ediciones Nobel, Oviedo, 2000, p. 17. Véase también Intencionalidad, Tecnos, Madrid, 1992 (orig.: 1983), pp. 13 ss. 


\section{La palabra como acontecer en la conversación. En diálogo con D. Davidson}

Acabamos de señalar que lo que se genera sin regla en la palabra posee también una conformación dinámica. Es un "ponerse de acuerdo". Esta puntualización nos remite directamente a la ontología del acontecimiento que subtiende la estructura dialógica del habla. La palabra es siempre, en cuanto diciente, el espacio de la inter-locución, de la relación entre un yo y un tú. Se comprende, partiendo de este principio elemental, que Gadamer haya insistido tanto en que el lenguaje presupone un acuerdo entre los hablantes. ¿Cómo podrían ponerse en relación si no es sobre el subsuelo de un entendimiento previo? ${ }^{36}$. Pero, como se dijo, lo asombroso es que éste no posee un comienzo absoluto; se forja en el movimiento mismo de su propia prosecución. El entendimiento intersubjetivo en el que se inserta la palabra posee, en definitiva, la forma de un acontecer. La «elaboración de un lenguaje común tampoco consistirá en la puesta a punto de un instrumento para el fin del acuerdo, sino que, igual que en la conversación, se confundirá con la realización misma del comprender y el llegar a un acuerdo" ${ }^{37}$. De este modo, Gadamer corrige el riesgo que rondó a la concepción heideggeriana del lenguaje y que terminó debilitando su impresionante penetración: el

${ }^{36}$ Esta resis implica la primacía del entendimiento respecto a la distorsión comunicativa, que ha conducido a Gadamer a una discusión con J. Habermas y K.-O. Apel. Como se sabe, éstos parten de la base de que la comprensión de sentido está siempre atravesada por autoengaños y distorsiones, por lo que el proceso de entendimiento no se resuelve desde sí, sino que está necesitado de una crítica de patologias que ha de recurrir al método de la explicación. Véase J. HaBermas, "La pretensión de universalidad de la hermenéutica" (1970), en La lógica de las ciencias sociales, Tecnos, Madrid, 1990, pp. 277-307 y K.-O. APEL, "Cientística, hermenéutica y crítica de las ideologias" (1971), en La transformación de la filosofia, Taurus, Madrid, 1985, vol. II, pp. 91-121. Gadamer insiste en que, para identificar, incluso, una comunicación como efecto de un trastorno en la comprensión hemos presupuesto ya el entendimiento de la cosa sobre la que se plantea la sospecha. La voluntad de comprensión se resuelve, así, en el diálogo mismo, en el intento de superar el malentendido. Véase "Retórica, hermenéutica y crítica de la ideología" (1967), en VM, II, pp. 225-243 y "Lenguaje y comprensión" (1970), en ibid., esp. pp. 181-183. Con el fin de proseguir el tema que nos ocupa, evito entrar en esta polémica.

${ }^{37} V M$, I, p. 466. Cfr. pp. 461-468. Atribuye Gadamer este descubrimiento a Aristóteles. Cuando el estagirita subrayó el carácter convencional del lenguaje (Aristóteles, De Interpretatione 2, 16a; 4,17 a) no pensaba que la convención puede ser concertada como un convenio explícito, sino que tiene lugar por mor del lenguaje. «La esencial conexión interior entre lenguaje y convención sólo dice que el lenguaje es un acontecimiento comunicativo en que los hombres concuerdan». H.-G. GADAMER, "La voz y el lenguaje" (1981), en Arte y verdad de la palabra, op. cit., p. 52. Véase también ibid., pp. 136-138. 
riesgo de hipostasiar el fenómeno del habla como una especie de absoluto contingente respecto al cual la dimensión pragmática de la comunicación es devaluada en cuanto instancia parasitaria o derivada, impotente para ejercer rendimientos propios ${ }^{38}$.

No hay, quizás, en el campo de la tradición analítica, un ámbito de investigación más próximo al que acabamos de esbozar que el que ha desplegado $\mathrm{D}$. Davidson. Heredero heterodoxo de Quine, ha vinculado la teoría del significado con la teoría de la interpretación. El relativismo ontológico quineano ${ }^{39}$ exhibe ya un paralelismo estructural notable con la hermenéutica. En primer lugar, porque hace depender la referencia lingüística al mundo de una pluralidad de marcos de lenguaje, cada uno de los cuales incorpora presupuestos ontológicos distintos y no es susceptible de una traducción completa desde los otros. En segundo lugar, porque comprende la textura de cada uno de los mundos lingüísticos de forma holista, es decir, como totalidades en las que los significados se incorporan en una globalidad de relaciones y dependencias. Todo ello, unido a la tesis según la cual el ámbito referencial del mundo es, finalmente, inescrutable, pues

${ }^{38}$ Ya en El ser y el tiempo, op. cit., Heidegger consideró al lenguaje como el estado de interpretado del habla (pp. $186 \mathrm{~s}$.), cuya tendencia inherente parece consistir en la transmisión repetida de lo que se habla y, así, en una caída en la inaurenticidad de las habladurias (\$35). "La investigación filosófica - dice expresamente- tiene que renunciar a la 'filosofía del lenguaje' para interesarse por las 'cosas mismas'" (p. 185). Ricoeur ha visto en esta propensión de la fenomenología del habla continental una criticable ontologización del lenguaje, que no media la dimensión del decir con la esfera estructural de la lengua (Cfr. P. RICOEUR, Le conflit des interprétations, París, Seuil, 1969, pp. 31-64, 80-101, 222-233). En la Kehre el problema adopta una forma distinta y se agudiza. Ciertamente, Heidegger ha reconocido el carácter dialógico del lenguaje. Éste «tiene lugar propiamente en la conversación", pero "la unidad de una conversación, sin embargo, consiste en que, en cada caso, en la palabra esencial está patente lo uno y lo mismo, en lo que nos unificamos y sobre cuya base estamos unidos" (M. HEIDEGGER, "Hölderlin y la esencia de la poesía" [1937], en Interpretaciones sobre la poesía de Hölderlin, Ariel, Barcelona, 1983, pp. 59-60). Con ello Heidegger acentúa la apertura de mundo previa en la que se sustenta el entendimiento y corre el riesgo de equiparar aquello sobre lo que es posible llegar a un acuerdo y aquello que sirve de base al acuerdo. La radical anterioridad de la apertura de sentido en el habla parece en Heidegger una instancia que no se deja penetrar por la productividad propia de la conversación efectiva. Apreciaciones similares encontramos en M. HEIDEGGER, De camino al habla, Odós, Barcelona, 1987 (orig.: 1959), cuando refiere las conocidas afirmaciones sobre el hablar del lenguaje. Véase sobre este tema C. LAFONT, La razón como lenguaje, Visor, Madrid,1993, pp. 80-87.

${ }^{39}$ Cfr. W.V. Quine, Relatividad ontológica y otros ensayos, Tecnos, Madrid, 1974 (orig.: 1969), pp. 43-91. 
se halla inmerso en la diversidad de las descripciones holistas, es correlativo respecto al presupuesto genérico de la experiencia hermenéutica: una pluralidad de horizontes o mundos de sentido en los que la cosa misma, nunca apresable como realidad en si, comparece.

Ahora bien, Davidson, incorporando estos elementos básicos, ha superado, además, el reductivismo cientificista de su maestro y ha transformado la invocación al relativismo en una afirmación del diálogo interpretativo ${ }^{40}$. El camino que conduce a esta mayor aproximación al ámbito hermenéutico gadameriano revela, al unísono, la primera diferencia a destacar. Davidson parte, de acuerdo con el motivo conductista de Quine, de la idea de que en el lenguaje nos comportamos como observadores de la conducta verbal del otro. Así, el pensamiento, que distingue a los humanos de los animales, es algo que en la comunicación nos atribuimos recíprocamente desde la perspectiva (externa) de la tercera persona ${ }^{41}$. El foso queda, en este mismo comienzo, inaugurado, pues la concepción hermenéutica asume que babitamos el lenguaje y que comprendemos al otro en la medida en que participamos (internamente) en la apertura de sentido que subriende la relación. Lo sorprendente es que el analítico haya llegado, desde este posicionamiento tan opuesto, a conclusiones convergentes con las del pensador alemán. Pues es el caso que la atribución de pensamiento presupone reconocer, como parte de la praxis verbal del otro, actitudes proposicionales, es decir, no sólo contenidos mentales, sino actos como los de "creer" o "saber", que imprimen a lo pensado intensionalidad semántica. Ahora bien, la suposición de dicha intensionalidad (que es el análogo analítico del sentido) exige que la aclaración recíproca de la conducta verbal constituya una interpretación e implique tener en cuenta el contexto del habla. La tesis central dictamina, pues, que «una creatura no puede tener pensamientos a menos que sea intérprete del habla del otro" y que ser hablante significa, ser intérprete ${ }^{42}$.

Tomando pie en este basamento, la filosofía davidsoniana indaga las condiciones de posibilidad del hecho interpretativo, a través del método de la interpretación radical. Se trata de suponer una situación en la que un sujeto

${ }^{40}$ Para Quine, los marcos lingüísticos que realmente proporcionan experiencia de verdad son los de la ciencia natural, con la cual la filosofía misma está en continuidad, en cuanto vehículo de una epistemologia naturalizada. Cfr. ibid., pp. 93-121.

${ }_{41}$ Cfr. D. DAVIDSON, "Pensamiento y habla" (1975), en De la verdad y de la interpretación, Gedisa, Barcelona, 1995, pp. 164-165.

42 Ibid., p. 166; cfr. pp. 164-172. 
tiene que interpretar un lenguaje completamente desconocido para él y ha de tomar como cauce tan sólo la observación de la conducta del extraño ${ }^{43}$. Y he aquí que este análisis arroja resultados que, prima facie, asumiría el hermeneuta. El planteamiento mismo supone que el acceso a lo real está ya siempre mediado por horizontes lingüísticos plurales y que éstos no son ámbitos cerrados: entre ellos puede lanzarse el puente de la comprensión. La referencia es, en último término, inescrutable, pero no es un en sí inalcanzable; está inserta en la diversidad y enlazada por el entendimiento. Por un flujo de interpretaciones, por cierto, que no puede culminar jamás en un esclarecimiento completo, pues el interpretar es inseparable de un principio de indeterminación ineludible ${ }^{44}$. No podríamos negar, hasta el momento, la profunda analogía. Es así como la cosa misma, según Gadamer, está presente en el lenguaje. No es una realidad separada de los horizontes de sentido, sino comprendida y aprehendida en ellos. Es comunicable en la variación incesante del diálogo, a través de la fusión de horizontes del yo y del tú o del pasado y del presente, y para ese proceso no hay término esperable. "Cuando se comprende se comprende de un modo diferente" ${ }^{45}$.

Las semejanzas se exacerban si preguntamos por el modo en que la realidad comparece en el seno del lenguaje. Entra en escena ahora otro elemento central de la concepción davidsoniana: el externalismo, según el cual existe un enlace directo entre significado y referencia, lenguaje y mundo. Un enlace cuya productividad, por lo demás, implica que son los eventos mismos los que determinan los estados mentales en virtud de su poder causal respecto al sujeto, que, por

43 Los contenidos básicos del planteamiento davidsoniano se encuentran, fundamentalmente, en Davidson, "Interpretación radical", en De la verdad y de la interpretación, op. cit., 137-151. Es especialmente clarificador también D. DAVIDSON, "Las condiciones del pensamiento" (1988), en Mente, mundo y acción (compilación), Paidós, Barcelona, 1992.

44 Este principio, deducido ya por Quine del fenómeno de la traducción, lo redescubre Davidson en la interpretación. Fundamentalmente, se desprende del holismo. Los significados están entrelazados en una red de interdependencias. La interpretación nunca alcanza certeza, pues para identificar las correlaciones precisas de una determinada afirmación tendríamos que poder acceder al todo lingüístico del otro, lo cual es imposible, dado que nosotros mismos portamos ya esquemas interpretativos que arraigan en nuestro propio entramado holístico de pensamientos y experiencias.

${ }^{45} V M$, I, p. 367. La fusión de horizontes acontece en el suelo dinámico de la historia efectual, en la que la conciencia misma del pasado queda acogida. En ese flujo se pone en obra la productividad de la distancia temporal. Véase ibid., pp. 360-378. 
así decirlo, está inmerso en la realidad ${ }^{46}$. Dicho esto, invito al lector a reparar en la extraordinaria convergencia entre esta concepción y la comprensión heideggeriana de la verdad como alétheia: el mundo, en ambos casos, no puede ser entendido como una construcción desde la subjetividad, sino como una instancia productiva de verdad que penetra al hablante y lo convierte en el lugar de una recepción. Si unimos a ello la pareja convicción davidsoniana, ya aludida, según la cual los lenguajes tamizan y conforman desde sí la referencia, será irremediable reconocer incluso una profunda alianza con la comprensión gadameriana de la unidad irrescindible entre palabra y cosa, entre el decir y el comparecer del mundo, una unidad que el hermeneuta ha escrutado con detalle perfilando lo que llama ser especulativo del lenguaje $e^{47}$.

Ahora bien, no dejará de sorprender tampoco la simultánea persistencia del hiato entre las ontologías del acontecimiento y de la factualidad. Y es que el esfuerzo de Davidson es el de hacer congeniar el ser interpretativo del lenguaje con un naturalismo materialista: tanto el polo del objeto como el del agente son realidades físicas regidas por estructuras legaliformes, que son asequibles, en principio, al método nomológico de la ciencia natural. Y ello implica que si el pensador analítico ha puesto un límite al cientificismo no es porque niegue una ontología según la cual lo que hay son factualidades, hechos representables en el plano horizontal de la descripción o la explicación. Es porque reconoce un déficit epistemológico insalvable en el acceso a dicha realidad factual, una fragilidad de nuestro arsenal gnoseológico, determinada por el holismo del lenguaje y la indeterminación que éste imprime a su tarea reconstructiva ${ }^{48}$.

46 El externalismo de Davidson, vinculado a lo que se viene llamando Teoría distal de la referencia, rompe con el dualismo quineano, que interpone entre el mundo y el sujeto un reino intermedio de entidades (las impresiones humeanas) y que constituye el "tercer dogma del empirismo*. Cfr. D. DAVIDSON, "De la idea misma de un esquema conceptual" (1974), en De la verdad y de la interpretación, op. cit., pp. 189-204 y "Estructura y contenido de la verdad» (1990), en J.A. NicOLAS/M.J. FRÁPOLLI (eds.), Teorias de la verdad en el siglo XX, Tecnos, Madrid, 1997, pp. 145-207.

47 $V M, \mathrm{I}, \$ 14.2$.

48 La asunción de una concepción materialista del mundo es expresa en todos los trabajos ya mencionados del autor. Su aplicación al sujeto constituye precisamente el basamento de su monismo anómalo en filosofia de la mente. Cfr. D. DAVIDSON, "Acontecimientos mentales" (1970), en Filosofia de la psicologia, Anthropos, Barcelona,1994, pp. 2-64. He intentado mostrar el hiato ontológico, en este campo, comparando el planteamiento de Davidson con el de Tugendhat. Véase L. SAEZ RUEDA, El conflicto entre continentales y analiticos, op.cit., cap. 6.1.3. 
La unidad entre palabra y cosa posee un significado muy distinto para Gadamer. Se cifra en esa estructura del diálogo a la que llama círculo hermenéutico de la comprensión ${ }^{49}$. La peculiaridad de ese círculo no reside sólo en que él mismo constituye el principio motriz del acontecer dialógico, sino en que permite entender los dos polos, subjetivo y objetivo, como acontecimientos recíprocamente constituyentes. El mundo del intérprete, por un lado, es el del interpretar mismo, un fenómeno vertical que consiste en la apertura de un mundo de sentido desde el suelo nutricio del pre-juiciar proyectante. Por otro lado, semejante proyección tiene lugar merced a esa especie de pasividad productiva que se pone en obra en la escucha, pues la interpretación recibe su dirección de la cosa misma, que es el interpretandum y la realidad en cuanto tal. Por su parte, la cosa misma debe entenderse como constituida, dado que comparece sólo en la interpretación. Pero es también, respecto a esta última, constituyente: se caracteriza por su poder apelativo. Ella demanda una dirección de la mirada, solicitando desde sí la germinación del comprender. Es esta recíproca interpenetración entre apelación y proyección la que revela la textura de lo real como el movimiento mismo de desvelamiento de sentido ${ }^{50}$. Su ruptura, por lo demás, sólo puede conducir a la voluntad de dominio sobre lo existente, pues convertiría a lo real, despojado de su ser apelativo, en una instancia inerme y al sujeto en un ser que no escucha ${ }^{51}$.

${ }^{49}$ Cfr. $V M, \mathrm{I}$, caps. 9 y 14 y $V M$, II, caps. 5 y 6 .

${ }^{50}$ Esta unidad compleja entre sujeto y mundo atraviesa la mundanización del sentido continental. Husserl la comprendió como correlación apriórica entre nóesis y nóema, entre constitución y automostración del sentido. En la profundización del uretroceso al mundo de la vidam este lazo se transforma en el nexo entre dos "acontecimientos" recíprocamente dependientes: el del "proyectar" prerreflexivo — que opera el Da-sein (Heidegger) o el «cuerpo inteligente» (Merleau-Ponty)y el del una "autodonación" que posee fuerza "apelativa" y cuya escucha presupone una especie de "pasividad productiva". Ello tiene lugar en la "comprensión situada", según Merleau-Ponty, orientada por los nexos de sentido que la situación reclama desde sí (MERLEAU-PONTY, Fenomenologia de la percepción, op. cit., parte tercera, cap. III, y Signes, Gallimard, París, 1960, pp. 20-31). O bien, se trata de una escucha que ha de "dejar ser al ente el ente que es" (HEIDEGGER, Vom Wesen der Wabrheit, en Wegmarken, V. Klostermann, Fráncfort del Meno, 1967, pp. 73-99, \$VIII).

${ }^{51}$ Cuando la filosofía confía en la naturaleza de la cosa como algo objetivo, ajeno a la interpretación, incurre en un objetivismo que silencia coactivamente el lenguaje de las cosas. Éste no es más que la otra cara del peligro opuesto: considerar la cosa como proyección del lenguaje. «Viene a significar que no estamos dispuestos, en general, a considerar a las cosas en su propio ser, sino que las supeditamos al cálculo del hombre y a su dominio de la naturaleza mediante la racionalidad de la ciencia. En un mundo cada vez más técnico hablar de una dignidad de las cosas resulta cada vez más incomprensible" (VM., II, p. 73. Cfr. pp. 71-80). En este sentido, la filosofía hermenéutica rebasa también la oposición entre externalismo e internalismo. Véase L. SAEZ RUEDA, $E l$ conflicto entre continentales y analiticos, op. cit., cap. 4.4.2. 
En lo que se refiere a nuestro tema central, esto significa que el acontecer del decir es el reverso del dar la palabra a la interpelación de la cosa. «Habitamos en la palabra. Ésta sale como fiadora de aquello de que habla»"

\section{La palabra como responsabilidad indisponible. A propósito de Wittgenstein y sus herederos}

Si la palabra es fiadora de aquello que en ella comparece, ¿no reclamará una fianza al hablante? $\mathrm{Al}$ plantear esta cuestión, quisiera reflexionar, por último, acerca de la circunstancia de que la palabra, en cuanto acontecimiento -indisponible, como se verá-, porta una demanda ética de la que nos hace responsables en el hablar.

Parece contradictorio pensar una responsabilidad respecto a algo de lo que no disponemos, algo que escapa a nuestra voluntad autónoma, como diría Kant. Pero, si lo pensamos bien, el imperativo es categórico porque no está sujeto al arbitrio. Él se nos da, es el factum de la razón. Ahora bien, para Gadamer, como para Heidegger, es la palabra la que porta un imperativo y manifiesta el poder de la autonomía, más allá de la subjetividad kantiana. Su carácter genuino implica que "se sostiene y que uno la defiende, que uno está por ella" ". Sin duda, se aúnan en la palabra un êthos y un lógos. Este último, no como ley del cogito, sino como el acontecimiento, más originario, del des-cubrir, en el que tiene lugar un légein ontológico y pre-reflexivo: la reunión y protección de la experiencia en la apertura comprehensiva de un mundo de sentido ${ }^{54}$. El primero, el êthos, radica en la apelación a la autenticidad que acompaña al acontecimiento: el darse de la cosa misma puede ser sostenido con nobleza o sofocado, bien porque se lo silencie, bien porque se devalúe su fuerza emergente. Así, por ejemplo, «hay tonos verdaderos y falsos, hay maneras de hablar que convencen $y$ otras que non ${ }^{55}$.

${ }^{52} V M$, II, p. 194.

${ }^{53}$ H.-G. GADAMER, "Acerca de la verdad de la palabra", en Arte y verdad de la palabra, p. 21.

${ }^{54}$ El Lógos originario acoge la fuerza imperante de la physis, es la utotalidad reunida y en sí estante del ente». M. HeIDEGGER, Introducción a la Metafisica, Nova, Buenos Aires, 1980 (orig.: 1953), p. 168. Gadamer sigue en esto al maestro. Véase Acotaciones hermenéticicas, op. cit., pp. 252 ss.

${ }^{55} \mathrm{H}$.-G. GADAMER, ibid., p. 252. El nexo entre verdad y autenticidad en la palabra es abordado por Gadamer en diversos lugares. Véase, por ejemplo, Arte y verdad de la palabra, op. cit., pp. 15-22 y «Poema y diálogo» (1988), en Poema y diálogo, Gedisa, Barcelona, 1999, pp. 142-156. 
Hagamos epoché por un instante del problema ético y precisemos el sentido de la autonomía indisponible del lenguaje, pues en este contexto se nos revelarán también los encuentros y desencuentros entre la tradición analítica y continental. Si al decir se le puede atribuir autonomía es, según Gadamer, porque se sustrae a la intencionalidad del sujeto y se atiene a la norma de la cosa misma, que no es otra que la de su poder apelativo ${ }^{56}$. Semejante irreverencia respecto a la subjetividad arbitraria la hace ya indisponible. Pero esto se manifiesta, sobre todo, en que, al inscribirse en el diálogo, es arrancada por la inmanencia del conversar, más allá de las querencias privadas de los que hablan ${ }^{57}$. Con extraordinaria belleza lo ilustraba Merleau-Ponty, recordándonos cómo "las usanzas de nuestro medio, la constelación de nuestros auditores, nos arrancan inmediatamente las palabras, las actitudes, el tono que resultan convenientes» ${ }^{58}$.

Pues bien, el carácter indisponible de la praxis linguística se hace patente, nos ha indicado Gadamer, en la afinidad entre la naturaleza del hablar y la del juego, pues en este último se pone en obra una inmersión en la que el jugador ha de «dejarse llevar» por su "espíritu de ligereza, de libertad», tal y como en la conversación nos abandonamos a la "ley de la cosa misma»" . Esta dimensionalidad del comprender invoca con irresistible fuerza un diálogo con el Wittgenstein de las Investigaciones filosóficas. Como se sabe, se concibe allí el significado como el uso de las palabras que se lleva a cabo en una pluralidad de juegos lingüísticos. En la praxis lingüística ocurre como en el ajedrez: sus reglas definen un campo de juego, pero no prescriben las jugadas específicas, que dependen de una inmersión participativa. En lo que queda inmerso el hablante, por lo demás, es en una forma de vida ${ }^{60}$. Ahora bien, este paralelismo puede leerse en clave continental

${ }^{56}$ Cfr. H.-G. GaDamer, Arte y verdad de la palabra, op. cit, pp. 31-34, esp. p. 32.

57 "La palabra se introduce a sí misma (...). Es el lenguaje mismo el que prescribe lo que es el uso lingǘstico. No se trata de ninguna mitologización del lenguaje, sino que el fenómeno expresa una exigencia del lenguaje no reductible a la opinión subjetiva e individual. Nosotros, ninguno en particular y todos en general, hablamos en el lenguaje, tal es el modo de ser del 'lenguaje'". VM, II, pp. 192-193.

${ }_{58}$ M. Merleau-Ponty, Fenomenología de la percepcion, op. cit., p. 123.

59 VM, II, p. 150. Cfr. VM., I, pp. 584 ss.; VM., II, pp. 256 ss.; el nexo entre comprensión y juego ha sido explorado también tomando como hilo conductor la experiencia estética: Véase H.-G. GADAMER, La actualidad de lo bello, Paidós, Barcelona, 1991 (orig.: 1977), esp. pp. 66-83, y $V M, \mathrm{I}$, pp. 143-182.

${ }^{60}$ Cfr. L. WITTGENSTEIN, Investigaciones filosóficas, Crítica, Barcelona, 1988 (orig.: 1953), \$\$ 19, 23, 241. 
o analítica. Y, de nuevo, en este último caso la óptica presupone una ontología de la factualidad. Así, Rorty entiende que los juegos lingüísticos no constituyen "aperturas de mundo" (en un sentido heideggeriano), sino "todos ya siempre abiertos", conformados por prácticas sociales descriptibles ${ }^{61}$. Desde esta perspectiva, la indisponibilidad del lenguaje reside en la simple circunstancia de que tales prácticas son el producto de "maridajes fortuitos entre personas que casualmente tropezaron la una con la otra " ${ }^{62}$. Son, pues, factualidades sociales lo que conforma el sustrato y el devenir de las formas de vida. Gadamer, por el contrario, asimila la textura de los juegos lingüisticos al acontecer de la comprensión y subraya la íntima afinidad entre Wittgenstein y Heidegger ${ }^{63}$. No extrañará al lector, por ello, que Rorty yerre en su interpretación de la filosofía gadameriana ${ }^{64}$. $Y$ puede decirse, en general, que, frente a esa concepción, para el continental las reglas de un juego lingüistico "acontecen de modo indisponible»: se muestran en el ejercicio mismo del jugar y abren un espacio en el que las jugadas concretas quedan "indeterminadas», abandonadas a una unidad inercial que rebasa la suma de las voluntades ${ }^{65}$.

Si he sometido al lector a este rodeo no es sólo para ilustrar el ser indisponible de la palabra por recurso a la unidad entre diálogo y juego. Es también, como anticipé, para acceder al rostro ético de la experiencia hermenéutica. El decir testimonia el ser de lo real pero no garantiza que éste se ponga en juego de modo genuino. La palabra puede ser inauténtica, como ocurre, por ejemplo, cuando se devalúa como simple instrumento de información o cuando declina en las

${ }^{61}$ R. RORTY, "Wittgenstein, Heidegger und die Hypostasierung der Sprache", en B. Mcguiness (ed.), Der Löwe spricht und wir können ihn nicht verstehen, Suhrkamp, Fráncfort del Meno, 1991, pp. 90 ss.

${ }_{62}$ R. RORTY, Contingencia, Ironía y solidaridad, Paidós, Barcelona, 1991 (orig.: 1989), pp. 126-7.

${ }^{63}$ Cfr. H.-G. GaDAmer, Arte y verdad de la palabra, op. cit., pp. 118-122.

${ }^{64} \mathrm{La}$ interpretación rortyana no puede ser calificada más que como una tosca simplificación. Véase R. RORTY, "El ser que puede ser comprendido es lenguajen, en VVAA, $E l$ ser que puede ser comprendido es lenguaje. Homenaje a Hans-Georg Gadamer, Madrid, Síntesis, 2003, pp. 41-59. Rorty asocia el mensaje gadameriano con la idiosincrasia nominalista y le basta con subrayar que ésta responde a la idea de que "cuando comprendemos algo lo hacemos con ayuda de una descripción" (p. 47). Pero esto no es casual. Rorty representa la versión naturalista del pensamiento postmoderno. Véase L. SAEZZ RUEDA, «Lo indisponible y el discurso. El legado de Heidegger en la polémica 'modernidad-postmodernidad'», Revista de Filosofia (Un. Complutense), vol. X (1997), n. ${ }^{\circ}$ 18, pp. 133-158, esp. pp. 148-150.

${ }^{65}$ Véase L. SAEZ RUEDA, El conflicto entre continentales y analiticos, op. cit., cap. 5.2.1. y pp. 325 ss. 
habladurías. Y si es así, reclama de nosotros una responsabilidad: la de preservar su fuerza productiva. Gadamer ha expresado con profunda sutileza lo que la palabra genuina, frente a la inauténtica, permite: intensifica la realidad. En efecto, lo que logra es que «lo dicho es(tá), de un modo más esencial, 'ahi'» pues el ser, en el habla auténtica "se acrecienta» ${ }^{66}$. Cierto que esto lo predica el hermeneuta de la poesía, la palabra "más diciente». Pero es porque ella revela de modo especialmente vigoroso lo que pertenece a la esencia de todo lenguaje. En particular, esa virtualidad yace en la palabra filosófica, esperando que la despertemos del acechante letargo ${ }^{67}$.

Y bien, ¿de qué depende que semejante poder de la palabra nos asista? ¿Cuáles son las condiciones de posibilidad de la intensificación de lo real? "De lo que se trata sobre todo es de liberar al lenguaje en sus posibilidades propias (...). Para ello es necesario encontrar la palabra precisa y también aprender el silencio elocuente: en síntesis, estar presente en el diálogo (im Gespräch sein)» ${ }^{68}$. A lo que apela Gadamer no es al mero hecho de formar parte del diálogo, sino al acontecimiento mismo del sostener la palabra y de mantener el rayo de su emergencia iluminadora. Todo lo que ese imperativo demanda del hablante se juega "in actu": en la dimensión intensiva del mantenerse-en-si ${ }^{69}$, de tal manera que la presencia a la que da cobijo no cese de emanar en el instante, alcanzando esa extraña perdurabilidad de su in-sistencia en la hospitalidad del momento ${ }^{70}$. No cabe duda:

${ }^{66}$ H.-G. GADAMER, "Acerca de la verdad de la palabra», en Arte y verdad de la palabra, op. cit., pp. 43-44.

${ }_{67}$ Cfr. ibid., p. 23, 30 y 42 y Acotaciones hermenéuticas, op. cit., pp. 248-249.

${ }^{68}$ Arte y verdad de la palabra, op. cit., pp. 127-128.

${ }^{69}$ Cfr. ibid., 47-48. Esta expresión define también para Ricoeur el sentido profundo de la responsabilidad en la existencia. Mantenimiento-de-sí es la traducción literal del término alemán que se refiere a la autonomía del que vive por sí mismo: Selbstständigkeit. Cfr. P. Ricoeur, St mismo como otro, Siglo XXI, México, 1996 (orig.: 1990), pp. 118 ss. El mantenerse-en-si es un acontecimiento y no una estructura, e implica un poder para atenerse a sí mismo, dejándose-ser.

${ }^{70}$ El lenguaje genuino, dice Gadamer, "permite que algo sea duradero en el momento" (Arte y verdad de la palabra, op.cit., p. 79) y el "mantenimiento de la proximidad": la palabra diciente retiene la huida a la que está expuesta la experiencia y procura así la "cercanía al ser» (ibid., pp. 4448). Derrida detecta aquí una metafisica de la presencia. Véanse los textos de su encuentro parisino con Gadamer en A. Gómez Ramos (ed.), Diálogo y deconstrucción, Cuaderno Gris, 1998. No puedo entrar en esta discusión. Sólo un guiño. La perdurabilidad a la que se refiere Gadamer se asemeja a esa que tiene lugar cuando el personaje de la gran novela de Proust recobra la fugacidad del pasado en el acto vivo del recuerdo: lo vivido alcanza una eternidad en el instante, que es un ser extratemporal (M. PROUST, El tiempo recobrado, Madrid, Alianza, 2000, p. 217). No porque esté 
las condiciones de la palabra genuina coinciden con aquellas que permiten el vigor de ese ser vertical de la palabra al que he llamado su ser-naciente y que se ponen en juego en el diálogo.

En este punto, el pensamiento de Gadamer se revela como un umbral. Aquel que, además de situarse en la ontología del acontecimiento, quede seducido por lo que el pensar gadameriano acaba de traernos al encuentro, se percatará de que toca con ello el problema de la salud y la enfermedad. El poder de la palabra para decir la verdad se juega en la salud de su ser diciente. ¿Depende, entonces, la verdad de un discurso sólo de las condiciones que permiten, en el plano horizontal del entendimiento, la defensa libre e igualitaria de pretensiones de validez (Habermas, Apel)? ¿No habrá que indagar, además, condiciones generativas de la vitalidad de los discursos, de la fortaleza o palidez de lo que en ellos se juega, es decir, del vigor de su ser-naciente?

fuera del tiempo, sino porque es otro tiempo que el lineal. Al tiempo genuino del acontecimiento (el Aión) le reconocía Deleuze una cualidad similar: es una eternidad intensiva que subtiende el devenir extensivo de Cronos. Cfr. G. Deleuze, Logica del sentido, Paidós, Barcelona, pp. 28-29, 73, 172. Con ello sugiero que no es necesario salir del pensamiento de la diferencia para dar crédito a lo que Gadamer está aquí pensando.

71 A Gadamer no se le ha escapado este problema. Véase El estado oculto de la salud, Gedisa, Barcelona, 2001 (orig.: 1993). Con las limitaciones de un conocimiento precario de problemáticas coimplicadas en este campo, he esbozado el horizonte de investigación aquí abierto en L. SÁEZ RUEDA, "¿Es posible una razón crítica sin recurso a Ideas Regulativas? El nexo entre las dimensiones reflexiva y existencial de la crítica de patologías», Isegoria, 26 (2002), pp. 257-275. 